\title{
USS Callister: universos de ficción y aprendizaje de
}

lenguas ${ }^{*}$

USS Callister: fictional universes and languages

learning

\section{USS Callister: universos de ficção e aprendizagem de}

linguas

TANIA LUCÍA MADDALENA ${ }^{a}$

ANA SEVILLA PAVÓN ${ }^{b}$

\section{Resumen}

El presente artículo parte de una reflexión teórica inspirada en el capítulo USS Callister, de la cuarta temporada de la serie de Netflix Black Mirror. A partir de este episodio, se pretenden comprender las posibilidades educativas de crear universos de ficción con el uso de la metodología del relato digital en el aprendizaje de lenguas extranjeras. Se presenta una experiencia pedagógica en la cual 40 alumnos del grado en Ingeniería Aeroespacial de la Universitat Politècnica de València, España, crearon relatos digitales en su clase de Inglés técnico a lo largo de un semestre. La escritura creativa, así como las competencias lingüísticas, interpersonales y digitales fueron algunas las principales competencias desarrolladas por los estudiantes durante el proyecto. El resultado fueron autorías creativas en relatos digitales de hasta 4 minutos de duración, donde el universo, las naves espaciales

\footnotetext{
Las autoras quisieran expresar su agradecimiento al proyecto iTECLA (Innovative Telecollaborative Environments for Language Acquisition, Ref. GV/2017/151), financiado por la Conselleria de Educación de la Generalitat Valenciana (Programa Subvenciones para la realización de proyectos de I+D+i desarrollados por grupos de investigación emergentes) durante el periodo 2017-2019, dentro del cual se incluye la presente investigación.

a Universitat Politècnica de València UPV/Universidad Internacional de La Rioja UNIR, Valencia, España. Doctora en Educación, e-mail: tlmaddalena@gmail.com

b Universitat de València, Valencia, España. Doctora en Lingüística Aplicada, e-mail: Ana.M.Sevilla@uv.es
} 
y las misiones intergalácticas sirvieron como motivación para el aprendizaje del inglés técnico.

Palabras clave: Universos de ficción. Relatos Digitales. Competencias. Aprendizaje de lenguas. Inglés técnico.

\begin{abstract}
This article is based on a theoretical reflection inspired by the chapter USS Callister, from the fourth season of the Netflix Black Mirror series. From this episode, we intend to understand the educational possibilities of creating fictional universes with the use of the digital storytelling methodology for foreign languages learning. A pedagogical experience is presented in which 40 students of the degree in Aerospace Engineering at the Universitat Politècnica de València, Spain, created digital stories in their technical English class throughout a semester. Creative writing, as well as linguistic, interpersonal and digital literacy were among the main competences developed by the students during the project. The result was the creative authorship of digital stories of up to 4 minutes in length, where the universe, spacecraft and intergalactic missions served as motivation for learning technical English.
\end{abstract}

Keywords: Fictional universes. Digital Storytelling. Competences. Language learning. Technical English.

\title{
Resumo
}

O presente artigo parte de uma reflexão teórica inspirada no episódio USS Callister, da quarta temporada da série Black Mirror. A partir do episódio, as autoras procuraram compreender as possibilidades educativas de criar universos de ficção com o uso da metodologia do Digital Storytelling na aprendizagem de línguas estrangeiras. Apresentase uma experiência pedagógica na qual 40 alunos da graduação em Engenharia Aeroespacial da Universitat Politècnica de València, Espanha, criaram narrativas digitais na aula de inglês técnico ao longo do semestre. A escrita criativa, as competências linguísticas, interpessoais e digitais foram algumas das principais competências trabalhadas pelos estudantes no projeto. O resultado foram autorias criativas materializadas nas narrativas digitais de até 4 minutos de duração, nas quais o universo, as naves espaciais e as missões intergalácticas foram a motivação para o aprendizado do inglês técnico.

Palavras-chave: Universos de ficção. Narrativas digitais. Aprendizagem de línguas. Inglês técnico. 


\section{Introducción}

El arte de contar historias acompaña a la humanidad desde la antigüedad. Según Bruner (2014), los seres humanos vivimos inmersos en un mar de historias: estas dan forma y sentido a nuestras experiencias vitales yes en estas historias donde nos relacionamos con otros, establecemos lazos, socializamos y aprendemos. En su libro "Realidad mental y mundos posibles" (1998), Bruner contrapone dos modalidades de funcionamiento del pensamiento: la lógico/científica y la narrativa. La primera está regida por hipótesis y principios, utiliza la categorización y la no contradicción en las conexiones formales y es, en definitiva, es el modo en que resolvemos las cuestiones de la vida práctica. La segunda, conocida como modalidad narrativa del pensamiento, se ocupa de las acciones humanas constituyendo, según el autor, la forma de pensamiento más antigua de la humanidad. Este pensamiento consiste en contar historias para uno mismo y para los otros. Al narrar estas historias, vamos construyendo significados a través de los cuales nuestras experiencias van adquiriendo sentido. Cada modalidad de pensamiento permite modos característicos de acceso a la realidad (AGUIRRE, 2012, p. 84). Siendo así, vivimos la mayor parte de nuestras vidas en un mundo construido sobre las reglas y mecanismos de la narración. Esto significa que todos, de algún modo, experimentamos el arte narrativo. En su obra "Fabricando historias: derecho, literatura y vida" (2014), Bruner expone sus ideas sobre cómo las historias son fabricadas (y no descubiertas) en el mundo. Según este planteamiento, la ficción se constituye como elemento central.

Las narrativas han sido expresadas de diversas formas a lo largo de la historia. Por miles de años, se contaron y transmitieron de forma oral, para después reproducirse a través de imágenes en las paredes de piedra y, seguidamente, dar paso a la escritura y a nuevos modos de comunicación surgidos a partir de la invención de la imprenta, la radio, el cine, la televisión y, en la actualidad, todo tipo de pantallas de dispositivos móviles y plataformas de comunicación. "Más que Homo Sapiens, somos Homo Fabulators", sustenta el investigador de narrativas transmedia Scolari (2013, p. 17), ya que los seres humanos amamos ver, escuchar y vivir buenos relatos. En la cibercultura, estos relatos se materializan en una combinación de lenguajes que 
posibilita la hypermedia (MADDALENA, 2018). Su difusión puede llegar a lugares antes impensables gracias a las conexiones digitales en red.

El contexto de la cibercultura presenta un escenario desafiante para la educación y para los docentes de las diversas áreas del conocimiento. El informe del proyecto europeo Transmedia Literacy ${ }^{1}$ (2018), que investigó en más de ocho países el uso que los jóvenes realizan de las tecnologías digitales y cómo aprenden con las mismas, concluye que es de gran importancia involucrar a los estudiantes en el diseño de actividades de aprendizaje transmedia, con recursos interactivos, generando un ambiente cercano y de motivación, que inspire las autorías creativas y la proactividad de todos los agentes implicados en el proceso de aprendizaje.

Partiendo de este contexto, el presente artículo expone una experiencia pedagógica realizada en la Universitat Politècnica de València (UPV), España, en el Grado en Ingeniería Aeroespacial, en la asignatura de Inglés técnico, de nivel intermedio-alto o B2 del Marco Común Europeo de Referencia para las Lenguas (MCER, CONSEJO DE EUROPA, 2017), durante un semestre lectivo (de septiembre a diciembre). Como proyecto pedagógico para el aprendizaje del inglés, se propuso la metodología del relato digital, que se basa en la creación de vídeos con un fuerte componente narrativo, donde el narrador o narradora utiliza diversos elementos digitales para contar una historia.

¿Por qué relacionar esta experiencia pedagógica con el capítulo USS Callister de Black Mirror? Como profesoras e investigadoras del área educativa, especialmente de lenguas y sus aplicaciones tecnológicas, la serie Black Mirror nos presenta críticas y reflexiones profundas sobre el uso de las tecnologías digitales y su impacto en la sociedad. Elegimos el capítulo USS Callister porque atañe de manera directa al contexto de los estudiantes de Ingeniería Aeroespacial. Ello es cierto no solo porque el personaje principal es el comandante de una nave espacial en que objetos y lugares como naves espaciales, universos, viajes en el espacio, etc. constituyen el imaginario del área; sino también porque vemos en este capítulo una posibilidad para analizar componentes clave de la creación de universos de ficción. En nuestro caso, exploramos la aplicación de los universos de ficción en prácticas pedagógicas,

\footnotetext{
${ }^{1}$ Más información disponible en: https://transmedialiteracy.org/ 
mientras que en el caso de Robert Daly (comandante de la nave espacial USS Callister) dichos universos se emplean como una forma de venganza.

\section{USS Callister: el poder de los universos de ficción}

La cuarta temporada de la serie Black Mirror se inauguró con el capítulo USS Callister. Su protagonista, Robert Daly, interpretado por el actor Jesse Plemons, encarna a un exitoso programador informático y diseñador de videojuegos, jefe tecnológico una empresa de videojuegos y tecnología punta, en la cual trabaja desarrollando el proyecto estrella de la empresa, el Infinity. Se trata de un videojuego que revolucionó el mercado, ya que permite a los usuarios jugar todos de manera simultánea en una plataforma en la nube. Curiosamente, para acceder al videojuego el usuario debe entrar en un estado de inconsciencia en la que un pequeño dispositivo circular, con forma de grano o microchip, toma el control del cerebro y transporta a los jugadores a la plataforma.

Lejos de mostrarse como una persona feliz, Robert es excesivamente introvertido y presenta serias dificultades de socialización en su entorno de trabajo, donde pasa largas horas del día, encerrado en su oficina. Aunque a primera vista pareciera que Robert dedica todas esas horas a mejorar su juego Infinity, la verdad es que ha creado un mundo de realidad virtual inspirado en su serie televisiva favorita, Star Trek ${ }^{2}$. A este mundo se conecta por medio del pequeño dispositivo circular que se coloca detrás de la oreja, tanto en su casa como desde su propio trabajo.

En este mundo virtual, Robert es el jefe absoluto de todo como comandante de la nave espacial, llamada USS Callister, que pilota junto a sus compañeros de trabajo. Estos compañeros habían sido previamente clonados virtualmente con muestras de ADN real que Robert había recogido en el trabajo, sin permiso de los mismos.

\footnotetext{
2 Star Trek: The Original Series, es una serie de televisión de ciencia ficción estadounidense creada por Gene Roddenberry que se transmitió desde el 8 de septiembre del 1966 hasta el 2 de septiembre del 1969. Ambientada en el siglo XXIII, la serie original sigue las aventuras de la nave estelar USS Enterprise (NCC-1701) y su tripulación, liderada por el capitán James T. Kirk (William Shatner), su primer oficial, el Sr. Spock (Leonard Nimoy), el director médico Leonard McCoy (DeForest Kelley) y la oficial de comunicaciones Nyota Uhura (Nichelle Nichols).
} 
El capítulo USS Callister provoca reflexiones en diversas líneas de análisis como: el uso y abuso de los videojuegos, la realidad virtual, la inteligencia artificial y la clonación humana, entre otros. No obstante, en el presente artículo interesa penetrar específicamente en el universo de ficción, el corazón de la historia de Robert quien, movido por sentimientos de enorme frustración y sed de de venganza, canaliza dichos sentimientos a través de la construcción de un universo paralelo, en este caso virtual, donde no existen ningún tipo de límites en la ejecución de su cruel y despiadada venganza.

En su invención, Robert no solamente transporta y extrapola a USS Callister su deseo de venganza, sino que también refleja su fanatismo por Star Trek. El escenario, los personajes que comandan junto a él y también los enemigos, personificados en monstruos intergalácticos, han sido recreados de manera minuciosa. Asimismo, una vez hemos desvelado la mezcla de componentes que constituye y da forma al universo de ficción, nos interesa profundizar en este concepto:

Entiendo la categoría de universo ficcional como un marco de referencias e historias con coherencia interna y reglas propias, que interactúa fuertemente a nivel intertextual con una o varias historias en cualquier formato. Estos universos de ficción proveen de un marco de referencias fundamental, que interactúa activamente con los personajes de la trama, a los cuales además provee de un trasfondo cultural y psicológico, determinando sus objetivos, sus razones y sus frustraciones, pero también su aspecto físico, sus capacidades y sus habilidades (RUQUET, 2013, p. 3).

El universo de ficción construido por Robert Daly en USS Calister utilizó como referencia la serie Star Trek. Esta inspiración determinó las características físicas de la nave, sus colores y tecnología, los paisajes del espacio y los viajes hacia nuevas tierras habitadas por seres extraterrestres. Los personajes que habitan su universo están definidos por el ADN de sus compañeros de trabajo pero, al mismo tiempo, encarnan a cada personaje de Star Trek. No solo los caracterizó sino que también incorporó un sistema de gobierno y comportamiento donde se repetían algunos rituales como: frases, saludos, procedimientos en las misiones y un beso a una chica al final de la misión cumplida. 
Robert Daly no consiguió salir de su propio universo, pues el género de la ciencia ficción siempre desafía los límites de lo posible. USS Callister ganó el premio Creative Arts Emmy a la mejor película de televisión en 2018 y la mayoría de críticas hicieron alusión al peculiar homenaje a Star Trek, que no se queda simplemente en un homenaje, sino que profundiza en otros aspectos, como los elementos más peligrosos del fanatismo hacia los videojuegos y los dilemas éticos en torno a la inteligencia artificial. Es un episodio que, sin lugar a dudas, deja profundas reflexiones.

¿Para qué sirven los universos ficcionales de la ciencia ficción? El consumo de este género, ya sea en formato literario impreso, interactivo, audiovisual o cinematográfico, presenta componentes de motivación e inspiración, ya que estimula la imaginación y nos sumerge en un universo de nuevas posibilidades. Mae Jemison, la primera mujer negra en viajar al espacio en 1992, citó en diversas entrevistas a la "Teniente Uhura", la oficial de comunicaciones de Star Trek, como una de sus inspiraciones para convertirse en astronauta. Este ejemplo es uno de los miles que podríamos citar de cómo estos universos de ficción actúan en el imaginario social, movilizando subjetividades. Como señala Eco (1992) en su obra "Seis paseos por los bosques narrativos", la principal función de la ficción es dar forma a la experiencia humana:

Los niños juegan con muñecas, caballitos de madera o cometas, para familiarizarse con las leyes físicas y con las acciones que un día deberán llevar a cabo en serio. Igualmente, leer relatos significa hacer un juego a través del cual se aprende a dar sentido a la inmensidad de las cosas que han sucedido, suceden y sucederán en el mundo real. Al leer novelas, eludimos la angustia que nos atenaza cuando intentamos decir algo verdadero sobre el mundo real.

Esta es la función terapéutica de la narrativa y la razón por la cual los seres humanos, desde los orígenes de la humanidad, cuentan historias. Lo cual es, al fin y al cabo, la función de los mitos: dar forma al desorden de la experiencia (ECO, 1992, p. 96-97).

Toda historia narrada crea un espacio de ficción pues, cuando creamos una narrativa, un breve relato o una historia, estamos inventando, "ficcionando". Hablamos de "ficciones" entendiéndolas como 'algo construido, algo moldeado', que es el sentido original de la palabra fictio del latín, pues significa formación, creación. En otras palabras, no es que las ficciones sean falsas, no factuales o solamente experiencias del pensamiento (GEERTZ, 1989, p. 26), sino que se trata de creaciones en las cuales "lo real" es solo uno de los componentes que entran en el universo narrativo. 
Partiendo de esta manera de entender la ficción y los universos ficcionales, consideramos que la narración de historias posee un potencial pedagógico inagotable, pues al narrar una historia el narrador, ya sea estudiante o profesor, se nutre de innumerables estrategias, entrelazando experiencias, memorias y ficciones. Ello da lugar a la escritura creativa y a la imaginación, las cuales pueden favorecer diversos aprendizajes como, en el caso que nos ocupa, el aprendizaje de lenguas extranjeras.

\section{El relato digital y sus aplicaciones pedagógicas en la enseñanza de lenguas}

La metodología del relato digital consiste en crear un vídeo breve, de hasta 4 minutos de duración, en el cual predomina el contenido narrativo. En el vídeo, el narrador comparte en formato audiovisual aspectos de su historia de vida o temática de interés, utilizando diversos recursos digitales como fotografías, imágenes, música, vídeos, sonidos, etc.

La utilización del concepto relato digital tuvo inicio en la década de los 90 en los Estados Unidos. Joe Lambert (2002) fue el primer autor en utilizar el término y sus experiencias de investigación con la narración de historias y trayectorias personales a lo largo de muchos años le inspiraron para desarrollar esta metodología. En 1994, Joe Lambert, Nina Mullen y Dana Atchley fundaron el Center for Digital Storytelling, denominado actualmente Storycenter, ${ }^{3}$ en Berkeley, California. El centro funciona sin fines lucrativos, proporcionando cursos de formación continua para personas y organizaciones que quieran compartir sus historias e iniciarse en las prácticas de creación de relatos digitales, promoviendo, así, cambios y transformaciones individuales y colectivas.

La metodología del relato digital fue incluida por Lalueza, Crespo y Camps (2008) entre las tres líneas de investigación emergentes relacionadas con la utilización de las tecnologías de la información y comunicación (TIC) en los procesos de socialización del individuo. Las experiencias que utilizan los relatos digitales como

\footnotetext{
3 Página web do Center for Digital Storytelling: http://www.storycenter.org/ 
forma de expresión y autoría, desde la infancia, en áreas tan variadas como la educación formal o informal, en la dinamización sociocultural, en la intervención terapéutica y en el desarrollo cultural comunitario, demuestran cómo el paso de la condición de espectador a la de narrador es fundamental en la socialización de los seres humanos. Los autores resaltan que "las posibilidades abiertas por las TIC en la construcción de narradores será, sin duda, un elemento fundamental en los estudios de los procesos evolutivos del futuro" (LALUEZA y otros, 2008, p. 63).

Según Lambert (2002), todo relato digital debe presentar siete elementos principales: el punto de vista, la pregunta dramática, el contenido emocional, la voz del narrador, la banda sonora, la economía narrativa y el ritmo de la narración. Estos elementos pueden clasificarse en dos fases de la creación de los relatos: la etapa de la escritura y la etapa de la edición posterior, obteniendo como resultado un vídeo de alrededor de 4 minutos de duración.

En su obra 'Digital Storytelling: A creador's guide to interactive entertainment", Miller (2014) distingue dos tipos de relatos digitales: en primer lugar, los "relatos digitales tradicionales", en los cuales el autor-creador sigue una narrativa que expresa un producto final acabado, con las secuencias de la historia fijas, en formato de vídeo corto; y, en segundo lugar, los "relatos digitales interactivos", que poseen un grado de interactividad variable. Ello significa que el autor-creador mantiene la trama de la historia en abierto, sin que la historia tenga una linealidad y cronología preconcebida. Las historias de este tipo pueden ser modificadas por los usuarios que accedan a ella, convirtiéndose así en co-autores de la misma y pudiendo, incluso, definir el final o posibles finales de la historia narrada.

En los últimos años, el número de propuestas didácticas en torno a la metodología del relato digital en contextos de enseñanza de lenguas ha ido en aumento. Así, numerosos estudios destacan el potencial del relato digital para fomentar el desarrollo de competencias del siglo XXI, entre las que se incluyen competencias directamente relacionadas con el aprendizaje de lenguas (SEVILLA-PAVÓN \& GIMENO-SANZ, 2018; MADDALENA \& SEVILLA-PAVÓN, 2014; SADIK, 2008; YANG \& WU, 2012; SYLVESTER \& GREENIDGE, 2009; GREGORI-SIGNES, 2008; DARVIN \& NORTON, 2016). 


\section{El proyecto "Relatos digitales aeroespaciales"}

La metodología del relato digital se implementó en el proyecto de "Relatos digitales aeroespaciales". Dicho proyecto se llevó cabo a lo largo de un semestre con 52 estudiantes del Grado en Ingeniería Aeroespacial que estaban cursando la asignatura de Inglés Técnico en la Universitat Politècnica de València (UPV), España. Esta experiencia ilustra cómo la metodología del relato digital se puso en práctica en el aula de lenguas extranjeras para fomentar el desarrollo de diversas competencias del siglo XXI (PARTNERSHIP FOR $21^{\text {st }}$ CENTURY SKILLS, 2009), como son las competencias lingǘsticas, interpersonales y digitales, así como el desarrollo de la creatividad y la motivación.

Asimismo, el proyecto se centró en procesos cognitivos de orden superior en las actividades que se realizan a la hora de crear relatos digitales, como son la lluvia de ideas, la planificación, creación, escritura colaborativa, revisión y publicación de contenidos para la transformación de información de fuentes y formatos diversos, poniendo en práctica también la comprensión, la comparación, la elaboración y contraste de hipótesis, el análisis y la síntesis, siempre teniendo en cuenta la necesidad de utilizar "andamios cognitivos", dentro de la Zona de Desarrollo Próximo (ZPD) propuesta por Vygotsky (1978).

El nivel de inglés de los 52 estudiantes que participaron en el proyecto era intermedio-alto, es decir, nivel B2 del MCERL (CONSEJO DE EUROPA, 2017). Se trataba de alumnos de primer curso, con edades comprendidas entre los 18 y los 20 años. Los estudiantes trabajaron en grupos para llevar a cabo el proyecto de creación de sus relatos digitales paso a paso. Las diferentes fases del proyecto iban desde la realización de una WebQuest introductoria que les permitió acceder a diferentes recursos informativos que les serían de utilidad más adelante en la creación de sus relatos digitales, hasta la etapa final del proyecto en que los estudiantes compartieron sus respectivos relatos, los evaluaron e intercambiaron comentarios y opiniones en relación a los mismos.

Los participantes escribieron diversas versiones de un guion que se convertiría en la narración oral de su relato; prepararon un guion visual o storyboard; grabaron sus 
voces; buscaron los diferentes elementos textuales y audiovisuales que luego sincronizarían con la narración y música; combinaron y editaron dichos elementos para darles forma de relato digital, añadiendo a continuación los subtítulos y créditos correspondientes; y, finalmente, compartieron su trabajo en Poliforma' $\mathrm{T}$, el entorno virtual de aprendizaje de la universidad.

El análisis de los datos de tipo cuantitativo y cualitativo obtenidos con el prey el post-cuestionario que los participantes rellenaron al inicio del proyecto y una vez concluido el mismo, permitieron conocer las percepciones y actitudes de los estudiantes en cuanto al proyecto. Del mismo modo, se analizaron las producciones de los participantes, la presencia de diferentes universos de ficción en cada uno de ellos y las valoraciones de los estudiantes en cuanto a los diferentes relatos digitales, las cuales expresaron mediante interacciones en el foro y la evaluación por pares a través de una rúbrica de evaluación.

Los cuestionarios constaban, en primer lugar, de 63 preguntas de opción múltiple, divididas en varias secciones: datos demográficos, y valoración global de los diferentes elementos del proyecto y de su contribución al desarrollo de diferentes competencias, en una escala Likert de 7 puntos. Estos datos cuantitativos se complementaron con los datos cualitativos obtenidos a partir de 11 preguntas abiertas en que los estudiantes podían incluir información adicional sobre sus percepciones.

Entre las competencias genéricas del siglo XXI mejor valoradas por los estudiantes se incluyen el trabajo colaborativo y la creatividad a lo largo de todo el proceso de creación, y las competencias interpersonales, de investigación, de organización, de toma de decisiones y de resolución de problemas, así como las digitales y el pensamiento crítico.

Por su parte, las competencias lingüísticas también fueron valoradas positivamente por los participantes en el proyecto, quienes destacaron la contribución del proyecto al fomento de la comprensión y expresión oral y escrita, la gramática y el vocabulario, las habilidades comunicativas y la adquisición de vocabulario para fines específicos del contexto técnico correspondiente, relativo a la ingeniería aeroespacial:

Además, la valoración y evaluación individual que los estudiantes hicieron de cada uno de los relatos digitales mediante la evaluación por pares destacó diversos aspectos relacionados con la creación de universos de ficción por parte de cada uno 
de los grupos participantes. Los relatos digitales mejor valorados fueron "The Thin Black Line" y "End of Year Trip". El relato "The Thin Black Line" destacó por el gran esfuerzo dedicado por sus autores en hacer una narración audiovisual impecable de un conflicto bélico con mensaje pacifista y que invitaba a la reflexión mediante un efectivo guion y el uso de un simulador de vuelo que les permitió a sus autores reflejar escenas aéreas de gran precisión y realismo.

En cuanto a "End of Year Trip", se trata de un relato con una trama simple pero muy del agrado de los estudiantes: un joven que había sido víctima de acoso escolar decide vengarse secuestrando el avión en que viajaba junto con sus compañeros de clase. De este relato los estudiantes valoraron positivamente, en primer lugar, el hecho de que se mostraran partes y aspectos técnicos relacionados con el funcionamiento del avión y, en segundo lugar, la emocionante manera en que los autores narraron la historia. Otros de los elementos que recibió una puntuación alta fue la originalidad y el esfuerzo de tratar de presentar los hechos con la mayor verosimilitud posible, por ejemplo, doblando a un presentador de informativos que daría la noticia del secuestro narrado en el relato. Los estudiantes también alabaron la acertada selección musical, que se adaptaba a los diferentes tipos de emoción que debía suscitar cada momento de la historia.

Otro relato digital evaluado positivamente fue "Genesis". Se trate de un original y complejo relato en que el universo habla en primera persona, narrando su historia y su visión de la existencia y del comportamiento humano. Esta historia fue muy valorada por invitar a la reflexión, adoptar un punto de vista diferente y utilizar impresionantes imágenes. Por su parte, las principales críticas negativas recibidas fueron en cuanto a la complejidad de la narración y a la ausencia de música.

En cuanto al relato "Space Survivors", este narra una aventura espacial en que los estudiantes van explorando y descubriendo los diferentes avances tecnológicos que han permitido la exploración espacial.

Finalmente, uno de los relatos considerados como los más inspiradores por parte de los participantes fue "Future Jobs for a Student of Aerospace Engineering". Dicho relato, como su propio nombre indica, describía las diferentes opciones laborales de 
un recién graduado en ingeniería aeroespacial. La mayoría de los estudiantes afirmó haberse hecho más consciente, gracias hasta este relato, de que el abanico de posibilidades laborales a su alcance dentro de la profesión de ingeniero o ingeniera aeroespacial era mucho más amplio de lo que se imaginaban. Ello, junto al entusiasmo con que los narradores describían cada uno de los trabajos, propició una muy buena acogida del relato por parte de los estudiantes.

En lo que respecta a las valoraciones de los relatos digitales por parte de los propios estudiantes, se realizó una evaluación por pares de los mismos. Para ello, utilizaron una rúbrica de evaluación en la que, en una escala del 1 al 10, se puntuaron los siguientes epígrafes: estructura y organización, gestión del tiempo, originalidad y claridad de la exposición, pronunciación, destrezas lingüísticas y nivel de inglés, destrezas orales y comunicativas, recursos utilizados, diario de reflexión y proceso creativo. Las evaluaciones a través de la rúbrica se complementaron con los comentarios y críticas constructivas vertidas a modo de interacciones de los estudiantes en el foro de discusión en línea habilitado a tal fin en el entorno virtual de aprendizaje PoliformaT. El nivel de participación en dicho foro fue muy alto, pues los estudiantes llegaron a intercambiar más de 300 mensajes, la mayoría de ellos relativamente extensos, en los diferentes hilos de discusión. A continuación, se muestra la traducción al español de algunos de los comentarios e interacciones de los estudiantes:

Marcos: En primer lugar, me gustaría daros la enhorabuena. Vuestro vídeo me parece muy informativo e interesante. Los dos aspectos negativos son el volumen de la música (en ocasiones, demasiado alto) y el hecho de que solo habéis incluido fotografías en lugar de clips de vídeo.

Pere: ;Buen trabajo! Habéis hecho un vídeo impresionante. La música es muy vibrante y apropiada para cada escena. Imagino que habrá requerido un proceso de edición difícil. Encontrar y recopilar todos esos ejemplos reales ha debido de ser muy costoso.

Yara: Me ha gustado mucho vuestro vídeo por la variedad de imágenes, fragmentos de vídeo y efectos que aparecen. Al ver el vídeo, es obvio que os habéis esforzado mucho en encontrar imágenes increíbles y la manera en que las habéis unido ha creado una atmósfera fascinante. Muy, muy buen trabajo.

Vicent: Hola, el tema de vuestro vídeo es muy original. Me ha gustado el modo en que habéis seleccionado los vídeos y narrado vuestra historia. Estoy bastante seguro de que habéis pasado mucho tiempo buscando y uniendo las imágenes, está claro que os habéis esforzado mucho al hacer vuestro relato digital. Habéis usado tanto vídeos como imágenes fijas, ;buena idea! La banda sonora también queda muy bien con el video (El tema central de 'Saw' y de 'In the House - In a Hearbeat' de la banda sonora 'Mass Effect 3' (podéis encontrarlo en Google). En cuanto a los aspectos técnicos, los 
silencios en algunas partes del vídeo han sido una gran idea, porque de este modo el espectador puede centrarse en las imágenes fijas, vídeos y texto. El único defecto que cabría señalar el volumen de la música que, a veces, es excesivo.

Pau: Al ver vuestro relato digital, lo primero que he pensado ha sido: "¿qué es esto, una película de miedo?" Jajajaja Pero, al verlo, ;me he dado cuenta de que habéis tenido una muy buena idea al crear un tráiler sobre vuestra pelicula! Con vuestras preguntas abiertas hacéis a los espectadores preguntarse de qué tratará vuestro vídeo y eso aumenta la expectación.

Joan: ¡Muy buen trabajo con el video! Habéis hecho francamente bien la edición de vuestra película. Además, ha sido una muy buena idea incluir un tráiler. El único inconveniente es que a veces la música no permite escuchar vuestras voces. A pesar de ello, habéis hecho un proyecto estupendo.

Eric: Muchas gracias por vuestros comentarios. Creíamos que el volumen de las voces sería aceptable, pero al hacer la última edición del vídeo, nos dimos cuenta de que la música se oía más que las voces y y a era demasiado tarde para volver y cambiarlo todo. Lo tendremos en cuenta de cara al futuro.

Mireia: iQué chulo! No me suelen gustar las peliculas de guerra, pero debo decir que habéis hecho un trabajo excepcional. Habéis empleado buenos recursos y les habéis sacad mucho partido. Creo que lo que verdaderamente encaja con el vídeo es la música, me encanta. ¡Un gran trabajo, chicos!

\section{Consideraciones finales}

La creación de universos de ficción en el contexto de una asignatura de Inglés Técnico para futuros ingenieros e ingenieras aeroespaciales permitió a los participantes desarrollar no solo competencias lingüísticas relacionadas con la adquisición y práctica de estructuras gramaticales y léxicas del inglés para fines específicos, junto con la capacidad de comunicación en dicha lengua, sino también una serie de competencias del siglo XXI, como son el trabajo colaborativo y en equipo, la creatividad, y las competencias interpersonales, de investigación, de organización, de toma de decisiones y de resolución de problemas, así como las digitales y el pensamiento crítico.

En la experiencia pedagógica vivimos un proceso creativo de gran potencia, manifestada tanto en las diversas narrativas del foro como también en los propios relatos digitales. Así, observamos cómo los estudiantes fueron articulando saberes específicos del área con el inglés técnico y la capacidad imaginativa con la escritura creativa en la hipermedia. En las creaciones audiovisuales, la invención de universos de ficción fue recurrente. 
Por medio de la narrativa nos construimos, reconstruimos $y$, de alguna forma, reinventamos el ayer y el mañana. Memoria e investigación se amalgaman en este proceso. Incluso cuando creamos los mundos posibles de la ficción, no desertamos lo familiar sino que fantaseamos sobre aquello que podría haber sido o podría ser. Por más que la mente humana haya ejercitado su memoria y refinado sus sistemas de registro, nunca consigue capturar el pasado de manera completa y fidedigna. Por otro lado, nunca consigue escapar del pasado. Memoria e imaginación son propiciadoras y consumidoras la una de la otra (BRUNER, 2014, p. 103)

Memoria e imaginación avanzan juntas en la creación de historias. Al crear el universo de ficción, varios componentes de lo cotidiano y de la imaginación se relacionan, conjugando experiencias, recuerdos y ficción.

¿Dónde radica la fuerza de la experiencia de narrar ficciones y micro-ficciones en contextos educativos? ¿Cuáles son las posibilidades que ofrece la creación de universos de ficción? De acuerdo con la experiencia narrada en el presente artículo, hemos accedido por cauces paralelos a los seguidos por USS Callister a lugares donde solo se accede a través del poder de la conjugación de la imaginación y la memoria. Así, la creación de universos de ficción y la narrativa de ficción permite ir más allá de lo dicho, superando barreras y yendo más allá de los límites para crear y tratar asuntos de interés, mediante la combinación de diversos elementos. De este modo, diversos aspectos de las vivencias personales del individuo y de su historia de vida se insieren en la narrativa de ficción, entretejiendo otros universos, dando rienda suelta a la creatividad y al modo de narrar y re-narrar el mundo, así como de narrarse a sí mismo en el mundo, lo cual abre nuevas vías y posibilidades de discusión, debate y reflexión.

\section{Referencias Bibliográficas}

AGUIRRE R. R. Pensamiento narrativo y educación. EDUCERE, Artículos Arbitrados, v. 53, n. 16, p. 83-92, ene.-abr. 2012. Disponível em: <http://www.redalyc.org/html/356/35623538010/>. Acceso en: 15 dez. 2017.

BRUNER, J. Realidad mental y mundos posibles. Barcelona: Gedisa, 1998.

BRUNER, J. Fabricando Histórias: Direito, Literatura, Vida. São Paulo: Letra e Voz, 2014.

CONSEJO DE EUROPA. Common European Framework of Reference for Languages: Learning, Teaching, Assessment. Companion Volume with new Descriptors. Estrasburgo: Council of Europe Publishing, 2017. 
DARVIN, R.; NORTON, B. Investment and language learning in the 21st century. Langage et société, v. 157, n. 3, p. 19-38, 2016. DOI 10.3917/1s.157.0019

ECO, U. Seis paseos por los bosques narrativos. Barcelona: Editorial Lumen, 1992.

GEERTZ, C. El antropólogo como autor. Barcelona: Paidós, 1989.

GREGORI-SIGNES, C. Integrating the old and the new: Digital storytelling in the EFL language classroom. Greta, v. 16, n. 1 e 2, p. 29-35, 2008.

LAMBERT, J. Digital Storytelling: capturing lives, creating community. Berkeley: Digital Diner Press, 2002.

LAZUELA, J. L.; CRESPO, I.; CAMPS, S. Las tecnologías de la información y de la comunicación y los procesos de desarrollo y socialización. In: COLL, S. C.; MONEREO, F. C. (coords.), Psicologia de la educación virtual: aprender y enseñar con las tecnologias de la información y la comunicacion. Madrid: Morata. p. 54-73, 2008.

MADDALENA, T. L.; SEVILLA-PAVÓN, A. El relato digital como propuesta pedagógica en la formación continua de profesores. Revista Iberoamericana de Educación, Monográfico 65, p. 149-160, 2014. Disponible en: <http://www.rieoei.org/rie65a09.pdf>. Acceso en: 10 mar. 2019.

MADDALENA, T. L. Digital Storytelling: uma experiência de pesquisa-formação na cibercultura. 198f. Tese (Doutorado em Educação) — Universidade do Estado do Rio de Janeiro, Rio de Janeiro, 2018.

MILLER, C. Digital Storytelling. A creator's Guide to Interactive Entertaiment. Burlington: Focal Press, 2014.

PARTNERSHIP FOR 21st CENTURY SKILLS P21 framework definitions, 2009. Disponible en: < http://p21.org/storage/documents/P21_Framework_Definitions.p df>. Acceso en: 20 jul. 2018.

RUQUET, E. Más allá de la literatura: la construcción de mundos en la narrativa popular. Revista El Toldo de Astier: propuestas y estudios sobre la enseñanza de la lengua y la literatura, año 4, n. 7, p. 43-56, oct. 2013. Disponible en: $<$ http://www.eltoldodeastier.fahce.unlp.edu.ar/numeros/numero-7/LLDRuquet.pdf $>$. Acceso en: 4 jul. 2018

SADIK, A. Digital storytelling: a meaningful technology-integrated approach for engaged students learning. Educational Tech Research Dev, n. 56, p. 487-506, 2008.

SCOLARI, C. Narrativas Transmedia: cuando los medios cuentan. Barcelona: Deusto, 2013.

SEVILLA-PAVÓN, A. Diseño, implementación y utilización de recursos multimedia para la enseñanz̧a y la evaluación del nivel B2 de inglés en contextos de educación superior a través del sistema InGenio. Tesis 
(Doctoral) - Valencia, Editorial Universitat Politècnica de València, 2013. Disponible en: <http://riunet.upv.es/handle/10251/29539>. Acceso en: 3 jul.2018

SEVILLA-PAVÓN, A.; GIMENO SANZ, A. Telecolaboración y creación de relatos digitales: una propuesta metodológica. En: GONZÁLEZ-LLORET, M.; Vinagre Laranjeira (Eds.): Comunicación Mediada por Tecnologías - Aprendizaje y Enseñanza de la Lengua Extranjera. Sheffield: 2018.2 Disponible en: $<$ https://www.equinoxpub.com/home/view-chapter/?id=27983n $>$. Acceso en: 20 jun. 2019.

SYLVESTER, R.; GREENIDGE, W.-L. Digital storytelling: Extending the potential for struggling writers. Reading Teacher, v. 63, n. 4, p. 284-295, 2009.

VYGOTSKY, L. S. Mind in society. Cambridge, MA: Harvard University Press, 1978.

YANG, Y.-T. C.; WU, W.-C. I. Digital storytelling for enhancing student academic achievement, critical thinking, and learning motivation: A year-long experimental study. Computers \& Education, v. 59, n. 2, p. 339-352, 2012. 